\title{
ESA SENTINEL 2 IMAGERY AND GBGEOAPP: INTEGRATED TOOLS FOR THE DEOSAI NATIONAL PARK
} MANAGEMENT PLAN

\author{
M. T. Melis ${ }^{1 *}$, F. Dessì ${ }^{1}$, P. Loddo ${ }^{1}$, A. Maccioni ${ }^{1}$, M. Gallo ${ }^{2}$, R. Ul Hassan ${ }^{2}$, M. Aurang Zaib ${ }^{2}$ \\ ${ }^{1}$ Dept. of Chemical and Geological Sciences, University of Cagliari, Area Scienze Geologiche: Cittadella Universitaria (BloccoA) \\ S.S. 554 bivio per Sestu - 09042 Monserrato (CA), Italy, titimelis@unica.it \\ ${ }^{2}$ EvK2CNR Pakistan, Skardu - Gilgit Baltistan, Pakistan Italian K2 Museum (PTDC Motels) Hamid Ghar Chowk, \\ Reg. N 4(5)EA/NGO/2009, riaz.hassan@evk2cnr.org \\ * Corresponding author \\ Commission III, WG III/1
}

KEY WORDS: Land Cover, ESA Sentinel, Crowd-generating data, Deosai National Park, Climate Change, Pakistan

\begin{abstract}
:
Deosai plateau, in the Gilgit-Baltistan Province of Pakistan, for its average elevation of 4,114 meters, is the second highest plateau in the world after Changtang Tibetan Plateau. Two biogeographically important mountain ranges merge in Deosai: the Himalayan and Karakorum--Pamir highlands. The Deosai National Park, with its first recognition in 1993, encompasses an area of about $1620 \mathrm{~km} 2$, with the altitude ranging from 3500 to 5200 meters a.s.l. It is known and visited by tourists for the presence of brown bear, but a large number of species of fauna and flora leave, and can be seen during the summer season. This high-altitude ecosystem is particularly fragile and can be considered a sentinel for the effects of climate changes.

Due to its geographic position and high altitude, the area of Deosai has never been studied in all its ecosystem components, producing high resolution maps. The first land cover map of Deosai with 10 meters of resolution is discussed in this study. This map has been obtained from Sentinel-2 imagery and improved through the new tool developed in this study: the GBGEOApp. This application for mobile has been done with three main ambitions: the validation of the new land cover map, its improvement with land use information, and the collection of new data in the field. On the basis of the results, the use of the GBGEOApp, as a tool for validation and increasing of environmental data collection, seems to be completely applicable involving the local technicians in a process of data sharing.
\end{abstract}

\section{INTRODUCTION}

\subsection{Thematic mapping and local knowledge}

The institution of a park and its management planning is a very long process that involves governments, technicians and researchers in consultation with the stakeholders.. The route often is very hard, because local habits and use of the territory is deeprouted, and each change can modify the equilibrium between human uses and environmental health. Hence, a direct involving of local communities can be seen as a way to arrive together to the main objective, that is the environmental safe and a correct human use, through a shared management plan. A management plan is a document that include all the information that support the proposed rules and the future development of the human activities in synergy with the recognized ecosystems. Moreover, the plan, through surveys collection of existing data creates a large number of thematic maps, that will be used to propose the zonation of the area in protected areas, according to their management objectives (Middleton and Lee, 2003).

The recognition of environmental conditions and the localization of the habitats and their connections can be supported by the land cover map. This map can be derived from satellite data and validated in the field. The choosing of high quality reference samples and field surveys are crucial for the production and validation of land cover maps. These activities are expensive and alternative approaches can be used (Zhao et al., 2017).

Over the last decade, volunteer geographic information (VGI), as a source of geographic information, has become an increasingly common trend as a special case of the more general Web phenomenon of user-generated content. In particular, the support of citizens to support land use and land cover mapping has been investigated during the recent years and the results demonstrated the adding value of local knowledge (Arsanjani et al., 2013), (Flanagin and Metzger, 2008), (Fritz et al., 2009). This public participatory mapping is considered as methodology of crowdsourcing, and are relevant in the topic of conservation planning (Brown et al., 2018). Many relevant projects dedicated to science programs are published into the SciStarter website (https://scistarter.com/about), demonstrating the increasing sensibility to biodiversity and environment conservation by the citizen involved (Paul and Hendriks, 2009).

Moreover, the use of a collaborative process for the recognition of the landscape characteristics is crucial for the maintenance of the environmental peculiarities and an improved land use legend system mainly focused on protected areas management can be proposed. As discussed in (Melis et al., 2017), three main goals will be achieved:

- The transition from the land cover to land use map;

- The social dimension of the process developed through a technological transfer can induce regional scientists and administrators to view science as a social, not simply technical, activity;

- A community awareness of the importance of a deep knowledge of land use and its interaction with environmental issues for ecosystem management.

This study is part of the United Nation Development Program (UNDP) Project "Improvement of Central Karakoram National Park (CKNP) Management System as Model for Mountain Ecosystems in Northern Pakistan", coordinated by the NGO (Non-Governmental Organization) EvK2CNR Pakistan. Following the approval of the CKNP Management system in 2016, UNDP pushed to export the positive experiences into another closed and very peculiar park of this area: the Deosai National Park (DNP). The support to the improvement of the existing DNP management plan through the acquisition of updated data is the main focus of this study. The involvement of local Organizations and Government Offices, and the participation of the communities to the development of the management rules increase the awareness and the sensibility to 
the climate threats and human inducted issues in this very sensitive area. Only few scientific reports and general maps are available for the area of Deosai, and they are mainly focused on the conservation of habitats of the brown bears, flagship species of the park (Nawaz et al., 2008).

To answer to the need of new field data collection, a dedicated tool to store environmental data has been developed. This tool is based on the use of a land cover classified map extracted from Sentinel 2 imagery, that can be utilized as base map in the field. The comparison between the map and the field characters can be used to standardize the observations on land cover and allows to improve the classification with updated information. The tool is dedicated to the park rangers with a very high knowledge of the landscape, flora and fauna, but with very poor facilities to collect and store geographic data. Moreover, in the area of Deosai, only in summer season (from July to October) data can be acquired because of weather conditions that prevent the access and mobility on the plateau. Hence, a smart tool can support this process with effective results.

\subsection{New tools for geo-data collecting}

Collecting spatial data with mobile phones is a new, innovative technology that can support the activities of land management and allows users to share and compare their data with others (Jeffrey E. Herrick et al., 2017). Some existing experiences are discussed on the use of specific applications for mobiles used to support technicians to input through mobiles data of soil profiles and land cover. These data are stored in remote databases and integrated with other information to provide updated data (Herrick et al., 2016).

In this framework, thanks to a positive experience of the authors in the EU H2020 Project FLOWERED (Melis et al., 2017), an application for mobile has been proposed to the rangers of the park and extended to technicians and students of the local organizations in Pakistan.

It is important to consider main requests of the proposed tool:

- $\quad$ Online and offline mode;

Access to a classified land cover map;

Automatic localization;

Collection of georeferenced and oriented photos;

Input data in different databases for each topic, according to personal knowledge;

- Access to a web resource, webGIS, to analyze the results and download data in standard formats for further processes.

\section{STUDY AREA AND DATASETS}

\subsection{Study area}

DNP covers an area of around $1,600 \mathrm{~km}^{2}$ of an alpine plateau in the western Himalaya, and represents the second highest plateau in the world after Changtang Tibetan Plateau. Its geographic position (Fig. 1), east of Nanga Parbat Peak in Northern Areas of Pakistan, in the Gilgit-Baltistan Province, at the convergence of the mountain ranges of Himalayan and Karakorum-Pamir highlands, made it feel the dynamics of climate and geology during the late Holocene (Meiners, 2005), (Iturrizaga, 1997). DNP is a small protected area, but its biodiversity , as recognized in deserves a high attention, as urged internationally (Baldwin and Fouch, 2018). The elevation of the plateau ranges from 3,324 to $5,397 \mathrm{~m}$, with a morphology mainly flat with gentle slopes, where a very large number of rivers flow in summer season. Indeed, the plateau is characterize by the presence of areas of wetlands and numerous small lakes. Their origin is due to snow and ice melting from the surrounding steep mountains, and on the presence of a permafrost table, which creates a thermokarst landscape (Brown and Romanovsky, 2008), (Karlsson et al., 2012), (Yoshikawa and Hinzman, 2003).

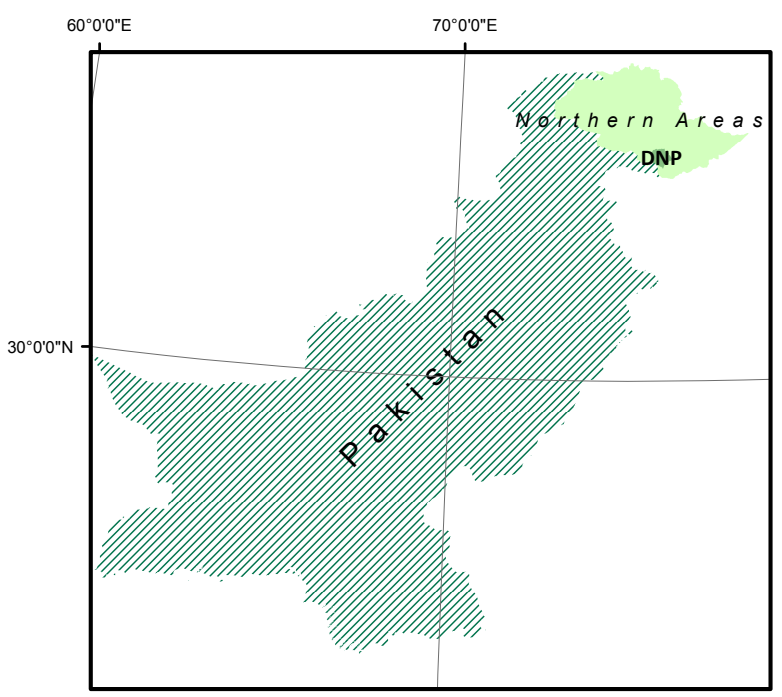

Figure 1. Localization of the Deosai National Park (DNP).

The highland ecosystem of Deosai is characterized by unpredictable, unstable, highly seasonal, and extreme environmental conditions. It is a typical high-altitude ecosystem, with mean daily temperatures ranging from $-20^{\circ} \mathrm{C}$ to $12{ }^{\circ} \mathrm{C}$, and annual precipitation varying between 510 and $750 \mathrm{~mm}$, mostly as snow (Nawaz et al., 2008). It is known and visited by tourists for the presence of brown bear, but a large number of species of fauna and flora leave, and can be seen during the summer season. This high-altitude ecosystem is particularly fragile and can be considered a sentinel for the effects of climate changes.

The herbaceous cover, as visible in the Normalized Difference Vegetation Index map extracted from Sentinel data (Fig. 2), is predominant and constitutes the pasture for livestock and wildlife, particularly brown bears (Nawaz et al., 2014). In these conditions, the overgrazing of livestock can constitute a threat for the ecosystem, and the monitoring of land cover changes with remote sensing data can be a real support for the conservation of wildlife of this protected area (Duan et al., 2020).

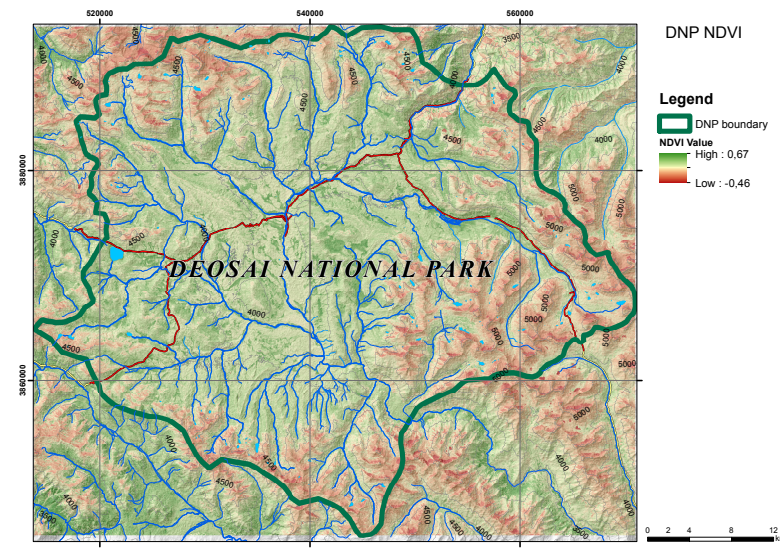

Figure 2. Normalized Difference Vegetation Index map.

\subsection{Datasets}

ESA Sentinel 2 data has been chosen to extract the land cover classification. On the basis of the conditions of the vegetation 
cover of the Deosai, a summer acquisition has been selected with a cloud cover $<10 \%$. In this study a single image has been used because the vegetation cover has its maximum in summer season, while in the other month the landscape is covered by snow. Moreover, it is very rare to find a cloud-free image in the summer months too. Considering these restrictions, a single multispectral image, acquired on August, 06 2018, has been used.

The topographic data have been extracted from NASA's Shuttle Radar Topography Mission (SRTM ) (https://www.usgs.gov/).

\section{METHODOLOGY}

\subsection{Approach}

The increasing availability of satellite data is a real value for the enhancement of environmental knowledge and the creation of the necessary tools for the land management and environmental monitoring. The possibility to integrate different source of geodata is growing and the methodologies to create thematic database are becoming very sophisticated. Moreover, the access to internet services and, in particular, to web mapping services is well developed and spread either between expert users than the citizens. In this study, in line with the IUCN's guidelines (Middleton and Lee, 2003), a series of maps has been realized for the management plan of the DNP, and the dedicated tool GBGeoApp, to improve the information extracted from satellite data ,is discussed in this study.

In order to obtain the expected results, the complete methodology adopted was based on the following steps (Fig. 3):

Land cover classification of Sentinel-2 data;

- Creation of the databases of the GBGEOApp, with the sharing of the contents with local technicians; Implementation of the app and the webGIS system

- Testing and training of the functionalities of the app in the field;

- Collection, storing and uploading of ground truth, ecosystem data, and data on human presence; Improvement of the land cover classification with the land use and publication of the data through a web-GIS platform (GEO DB).

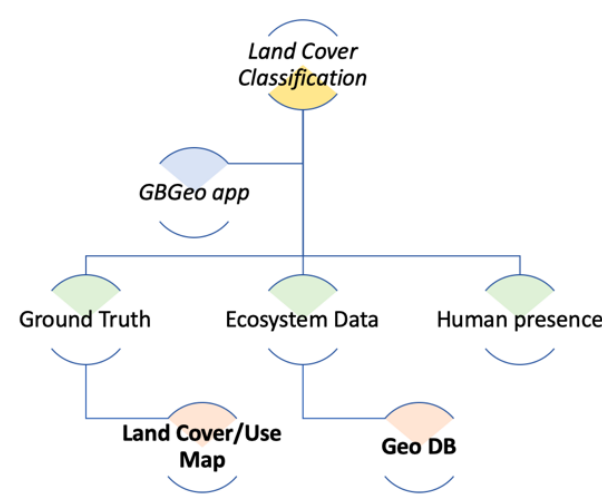

Figure 3. Workflow of the approach.

\subsection{Land cover classification}

The Land Cover map has been obtained through a supervised classification of the Sentinel-2 imagery. In order to classify the remote sensing image, the widely-used parametric classifier maximum likelihood classification (MLC) algorithm was applied. Using visual interpretation of the underlying very high resolution imagery, experts interpreted the image based on the land cover type visible, which includes trees, shrubs, water bodies, etc. This information was then translated into the legend using the UN LCCS (United Nations Land Cover Classification System developed by Food and Agriculture Organization- FAO) as a basis. In Table 1, the adopted legend is provided.

\section{DNP Land UNLCCS classes and definition}

Cover classes

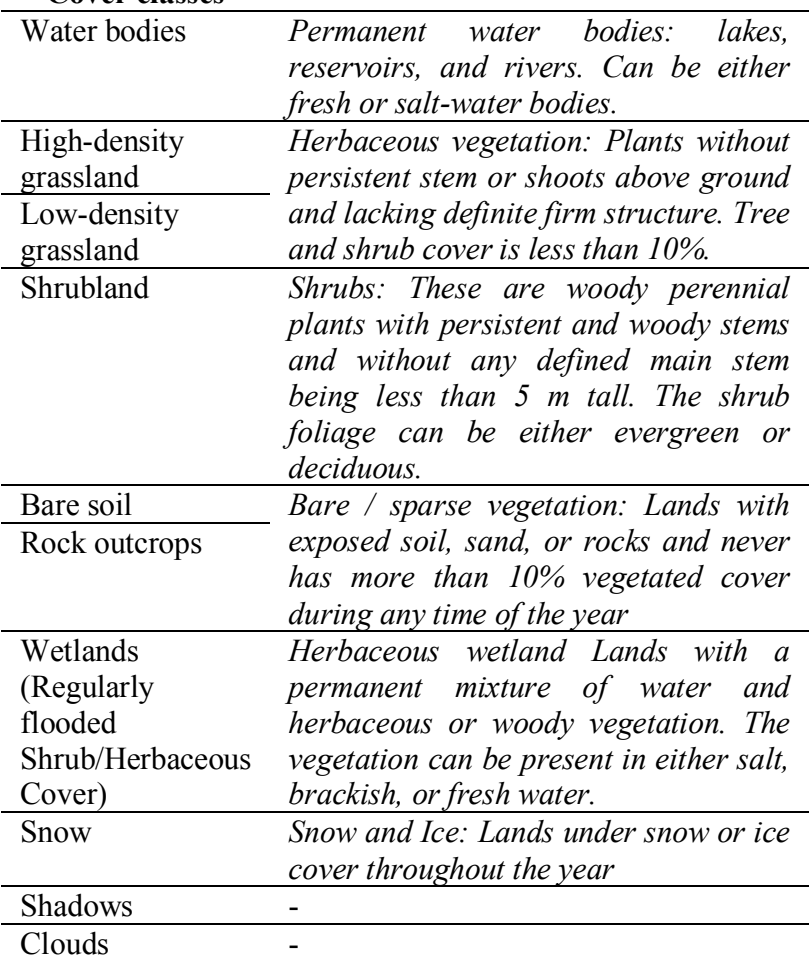

Table 1. The Land Cover legend

The UNLCCS system was designed as a hierarchical classification, which allows adjusting the thematic detail of the legend to the amount of information available. Training areas were established by choosing one or more polygons for each class. Pixels fall within the training area were taken to be the training pixels for a particular class. In order to select a good training area for a class, the important properties taken into consideration are its uniformity and how well they represent the same class throughout the whole image.

To select the most optimal training sites (spectral features), the comparison with Google Earth and Open Street Map data, as information with very high resolution, or already classified, was done. The Land cover map was loaded on PostGIS, catalogued in Geoserver and published through the webGIS, ready for the downloading and using with the app.

\subsection{The new application for mobile}

GBGEOApp reflects the purpose to share with the local technicians data on land use, through a process of direct involvement. Additionally, the app is dedicated to the collection of local geo- information on land use, fauna, flora, nomads and livestock, including the communities in a participative approach as the local actors. All collected data are directly linked to the land cover map, based on the classification of ESA Sentinel2 data. This approach permits to correlate the land cover to one or more specific land uses because GBGEOApp has been created with the purpose to be ready for ground truth data collection and validation. The existing issue of potential lack of network has been overcome with the ability to use the app in off-line mode (Fig.4). 
The app has been developed with an open source SDK called Ionic Framework for iOS and Android systems, and it is available for downloading at http://95.110.144.131/geoportal/app.

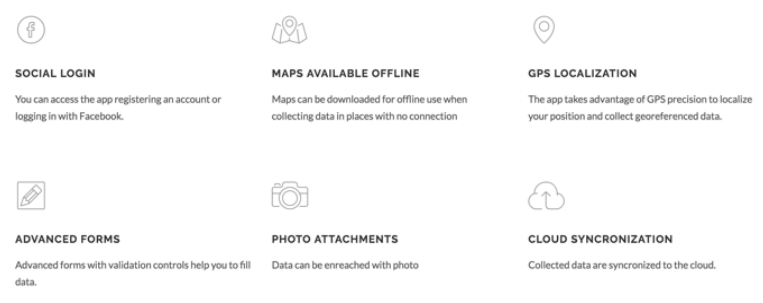

Figure 4. GBGEOApp: main features.

GBGEOApp allows to input automatically the localization of the point. The point appears on the map, using the GPS's position from the mobile (Fig. 5a,). Using this approach, positioning errors can be avoided. Starting from the main windows for the input of points, data collection is divided into 6 sections (Fig. 5b): Fauna, Flora, Nomad, Livestock, Landcover, and Critical point.
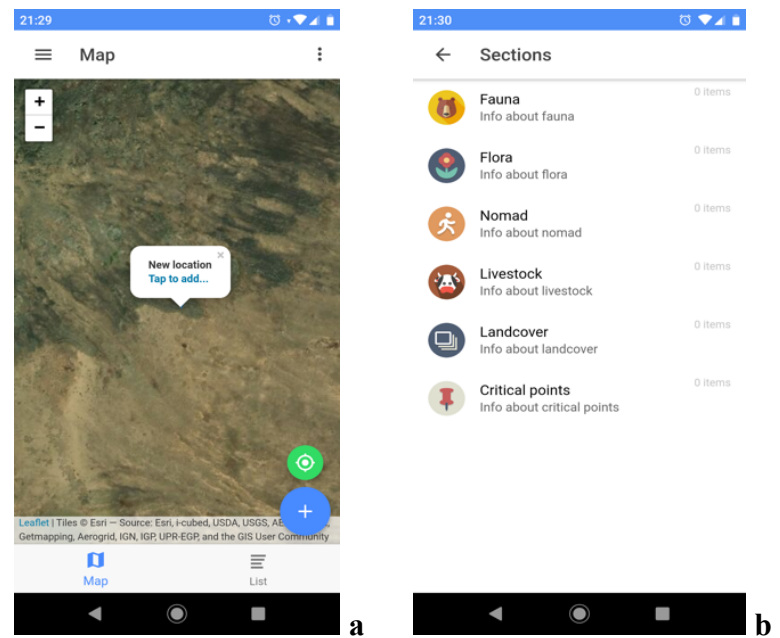

Figure 5. GBGEOApp: a) point input; b) sections.

For each section, a list of requested information is provided. Concerning land cover topic, first step is the downloading of the land cover map that can be used as visible layer on the screen. Following information on land cover can be given: i) Land cover class, the item can be chosen from drop-down menu; ii) Land cover coverage (\%); and iii) Land Use. One or more oriented picture can be taken.

With these information, a validation/update of the land cover in the point of interest can be done. Moreover, land use can be improve the description of the classes. These steps are very simple, and can be done in offline mode. When the network will work, all these point that have been stored into the mobile, will be uploaded in the remote database through a tool of synchronization with the server. All data collected within this activity are available for the technicians and the scientific community through a specific and dedicated web portal based on SHARE-GeoNetwork well proven architecture, based on open data philosophy (Melis et al., 2013), (Melis et al., 2014), (Mattavelli et al., 2016).

\section{RESULTS}

\subsection{Land cover map validation}

The Land cover map is shown in Fig. 6. This map has been obtained by the application of the MLC approach. This pixelbased method is recognized as a tool that generally produces similar or better classification accuracy than other classifiers (Yang et al., 2009), (Burai et al., 2015). Moreover, the choose of a pixel-based classification is supported by the characteristics of the vegetation cover on the Deosai plateau. The vegetation is natural, there are no crops or regular parcels (geometric features), The vegetation classes are sparsely distributed and with a high fragmentation.

Two steps of validation were applied: the first one using ground truth points extracted from the photointerpetation of Sentinel2 multispectral image, compared with Goolge Earth data, and the second validation was done using the data collected in the field though the app. This second validation was focused to provide the thematic accuracy.

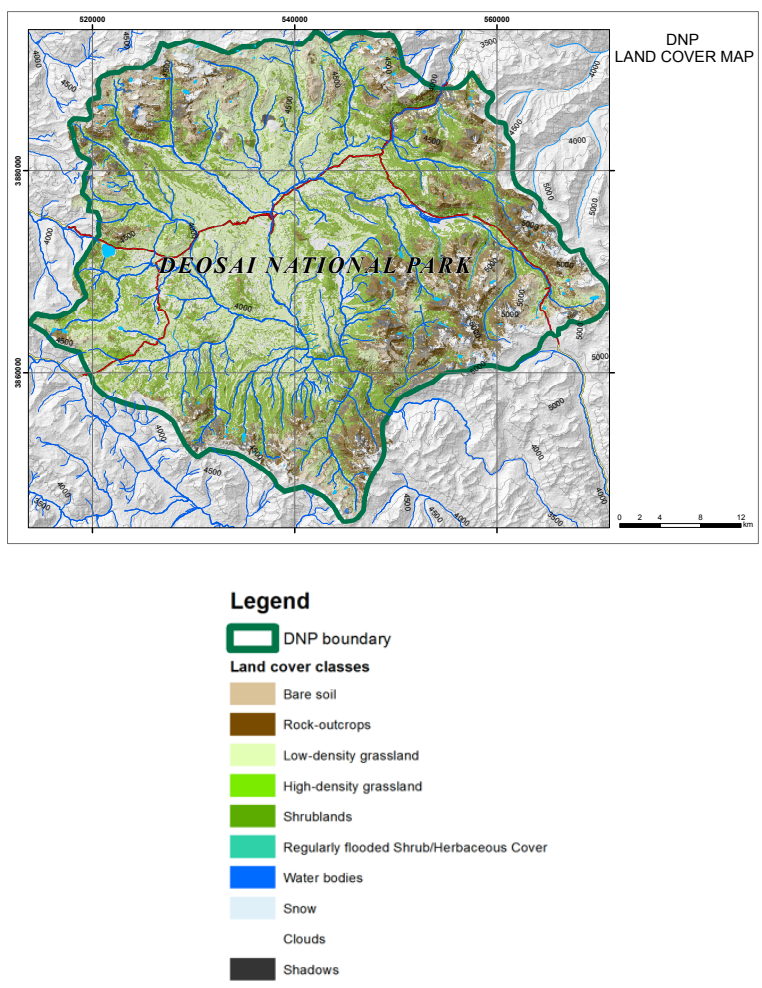

Figure 6. Land cover map and legend.

The accuracy assessment of the MLC was determined by means of a confusion matrix, comparing, on a class-by-class basis, the relationship between reference data (ground truth) and the corresponding results of the classification (Lillesand, 2006).

The results of the accuracy is shown in Table 2. We can observe that the classes "High-density grassland" and "Wetlands" show the lower values respectively of User and Producer Accuracy. Indeed, from the Confusion matrix, results that in the class "High-density grassland", some pixel are classified as "Regularly flooded Shrub/Herbaceous Cover".

Furthermore, two measures of overall behaviour of the MLC can be determined by the overall accuracy and Kappa coefficient. These two measures in the land cover classification of Deosai 
resulted respectively of $87 \%$ and 0.85 , demonstrating the good performance of the classification.

The second step of validation was conducted with the data collected in the field. The first field activity for the testing and collection of data has been done on September 2019. After some brief classes of training, the acquisition of data started.

More than 50 points where collected by technicians during three days of activities.

\begin{tabular}{lll} 
Classes & $\begin{array}{l}\text { Producer } \\
\text { Accuracy }\end{array}$ & $\begin{array}{l}\text { User } \\
\text { Accuracy }\end{array}$ \\
\hline Water bodies & $92,97 \%$ & $96,75 \%$ \\
\hline High-density grassland & $88,46 \%$ & $54,76 \%$ \\
\hline Low-density grassland & $93,33 \%$ & $70,00 \%$ \\
\hline Shrubland & $93,10 \%$ & $90,00 \%$ \\
\hline Bare soil & $82,43 \%$ & $92,42 \%$ \\
\hline Shadows & $88,37 \%$ & $95,00 \%$ \\
\hline Clouds & $100,00 \%$ & $100,00 \%$ \\
\hline Wetlands & $74,49 \%$ & $93,59 \%$ \\
\hline Snow & $92,31 \%$ & $92,31 \%$ \\
\hline Rock outcrops & $87,50 \%$ & $64,81 \%$
\end{tabular}

Table 2 Producer and User Accuracy of the MLC map.

All the data collected in the field were uploaded in the web portal and made available for the further analysis.

The results were compared with the land cover map to verify the thematic accuracy. The obtained values confirm the accuracy of the map. Two land cover classes can give some issue of interpretation. Comparing the assignment in the field with the land cover map, results that, some areas classify as Low-density grassland, have be classified in the field as bare soil, rock outcrop, or high density grassland. In the same way, Regularly flooded Shrub/Herbaceous class has been defined as shrubland (Table 3).

\begin{tabular}{cl}
$\begin{array}{c}\text { Land Cover } \\
\text { Map }\end{array}$ & \multicolumn{1}{c}{$\begin{array}{c}\text { GBGEO app } \\
\text { Ground Points }\end{array}$} \\
\hline Low-density grassland & Bare soil \\
\cline { 2 - 2 } & Rock outcrops \\
\cline { 2 - 2 }
\end{tabular}

High-density grassland

Regularly flooded

Shrublands

Shrub/Herbaceous cover

Table 3 Different interpretations of two classes in the field.

The meaning of these different interpretations can be given as following:

Misinterpretations of low-density grassland: in the field, the extension of the land cover class is not always simple to define, and the association of a local observation at a broader scale has to be considered;

- Misinterpretations of Regularly flooded Shrub/Herbaceous cover: the definition of this class is strictly connected to the presence of water or very wet soil; this condition can change rapidly during the summer season and can obviously change from one year to another.

In both cases the ancillary data, as the georeferenced pictures of the survey, can give the correct interpretation to the data.

Considering these two limitations, the records resulting from field surveys through the GBGEOApp can be used to improve the knowledge and to update existing maps.

\section{CONCLUSIONS}

This study confirms that the integration of remote sensing techniques and new technological approach for field survey can decrease the cost of the collection of new data. This is particularly important in remote areas, where the field activities have to be concentrated only in very few months in a year.

As discussed in (Arsanjani et al., 2013), the development of web 2.0 technologies allows to involve new actors in acquiring geoinformation. VGI, citizen science and crowd-generating data can be considered a new approach to improve the environmental knowledge.

In Deosai, the experience with the local rangers, supported by students and citizens can be considered very positive and effective not only for the results obtained by the field validation of the map, but mainly for the new interest for satellite data and its real using demonstrated by these persons.

The dataset was used to assess the resultant land cover/land use map. The obtained Kappa index at $85 \%$ proves that using Sentinel 2 data, the expected results can be used to build a land cover change monitoring system, as tool for the park management.

As suggested by (Arsanjani et al., 2013), the heterogeneity if the data collected in the field by non-experts can be overcome considering the ancillary date, like photos.

The first results are very interesting and can be summarized in two main considerations:

- $\quad$ More than fifty points of validation were collected by each technicians through the GBGEOapp in three days of field work in this mountainous area. The points were uploaded and used for the validation.

- The first land cover map of DNP with 10 meters of resolution has been realized. The thematic and spatial accuracy of this classification is very high, only the description of two classes has been changed on the basis of the field validation.

Beside of the problem of overgrazing and soil degradation, the most important issue is associated to the areas with the water bodies and wetlands, that during the summer season are fed by glacier/snow, and permafrost melting. These areas and the surroundings are crucial for the flora and fauna living and stay. They are clearly subjected to the global warming, and for these reasons have to be considered for a specific monitoring program. This study enhanced the importance and effective role of satellite data for the deep knowledge of remote areas. The use of the GBGEOApp, as a tool for validation and increasing of environmental data collection, seems to be completely applicable involving the local technicians in a process of data sharing. We think that it will also empower local communities to take responsibility for the integrated-sustainability of the natural resources, promoting local knowledge on the basis of a scientific and technological approach.

These fragile ecosystems show very hard threats mainly due to anthropic pressure, and stressed by climate change conditions. Due to its geographic position and high altitude, the area of Deosai has never been studied in all its ecosystem component, producing high resolution maps. 
The idea to improve the classification results with ground data on land use has been supported, proposing to the local technicians the using of the new GBGEOApp.

This study builds on and improves the results obtained by the writers in a previous study in which an app was designed and utilized to collect data on water quality and share with local technicians through a web platform based on Geonetwork system (Melis et al., 2017). All data collected within this activity are available for the scientific community through a specific and dedicated web portal based on SHARE-GeoNetwork.

\section{ACKNOWLEDGEMENTS}

This study is part of the United Nation Development Program (UNDP) Project "Improvement of Central Karakoram National Park (CKNP) Management System as Model for Mountain Ecosystems in Northern Pakistan", coordinated by the NGO (Non-Governmental Organization) EvK2CNR Pakistan.

\section{REFERENCES}

Arsanjani, J.J., Helbich, M., Bakillah, M., 2013. Exploiting Volunteered Geographic Information To Ease Land Use Mapping Of An Urban Landscape. Int. Arch. Photogramm. Remote Sens. Spatial Inf. Sci. ISPRS XL-4/W1, 51-55.

Baldwin, R.F., Fouch, N.T., 2018. Understanding the Biodiversity Contributions of Small Protected Areas Presents Many Challenges. Land 7. https://doi.org/10.3390/land7040123

Brown, G., McAlpine, C., Rhodes, J., Lunney, D., Goldingay, R., Fielding, K., Hetherington, S., Hopkins, M., Manning, C., Wood, M., Brace, A., Vass, L., 2018. Assessing the validity of crowdsourced wildlife observations for conservation using public participatory mapping methods. Biological Conservation 227, 141-151. https://doi.org/10.1016/j.biocon.2018.09.016

Brown, J., Romanovsky, V.E., 2008. Report from the International Permafrost Association: state of permafrost in the first decade of the 21st century. Permafrost and Periglacial Processes 19, 255-260. https://doi.org/10.1002/ppp.618

Burai, P., Deák, B., Valkó, O., Tomor, T., 2015. Classification of Herbaceous Vegetation Using Airborne Hyperspectral Imagery. Remote Sensing 7, 2046-2066. https://doi.org/10.3390/rs70202046

Duan, P., Wang, Y., Yin, P., 2020. Remote Sensing Applications in Monitoring of Protected Areas: A Bibliometric Analysis. Remote Sensing 12. https://doi.org/10.3390/rs12050772

Flanagin, A.J., Metzger, M.J., 2008. The credibility of volunteered geographic information. GeoJournal 72, 137-148. https://doi.org/10.1007/s10708-008-9188-y

Fritz, S., McCallum, I., Schill, C., Perger, C., Grillmayer, R., Achard, F., Kraxner, F., Obersteiner, M., 2009. Geo-Wiki.Org: The Use of Crowdsourcing to Improve Global Land Cover. Remote Sensing 1, 345-354. https://doi.org/10.3390/rs1030345

Herrick, J.E., Beh, A., Barrios, E., Bouvier, I., Coetzee, M., Dent, D., Elias, E., Hengl, T., Karl, J.W., Liniger, H., Matuszak, J., Neff, J.C., Ndungu, L.W., Obersteiner, M., Shepherd, K.D., Urama, K.C., van den Bosch, R., Webb, N.P., 2016. The LandPotential Knowledge System (LandPKS): mobile apps and collaboration for optimizing climate change investments.
Ecosystem Health and Sustainability 2, e01209. https://doi.org/10.1002/ehs2.1209

Iturrizaga, L., 1997. The valley of Shimshal - a geographical portrait of a remote high mountain settlement and its pastures with reference to environmental habitat conditions in the NorthWest Karakorum (Pakistan). GeoJournal 42, 303-328. https://doi.org/10.1023/A:1006869406576

Jeffrey E. Herrick, Jason W. Karl, Sarah E. McCord, Michaela Buenemann, Corinna Riginos, Ericha Courtright, Justin Van Zee, Amy C. Ganguli, Jay Angerer, Joel R. Brown, David W. Kimiti, Rick Saltzman, Adam Beh, Brandon Bestelmeyer, 2017. Two New Mobile Apps for Rangeland Inventory and Monitoring by Landowners and Land Managers. Rangelands 39, 46-55. https://doi.org/10.1016/j.rala.2016.12.003

Karlsson, J.M., Lyon, S.W., Destouni, G., 2012. Thermokarst lake, hydrological flow and water balance indicators of permafrost change in Western Siberia. Journal of Hydrology 464-465,

459-466.

https://doi.org/10.1016/j.jhydrol.2012.07.037

Lillesand, T.M., 2006. Remote Sensing and Image Interpretation. John Wiley \& Sons, Inc., Hoboken, NJ, USA.

Mattavelli, M., Strigaro, D., Frigerio, I., Locci, F., Melis, M.T., De Amicis, M., 2016. The IDB: An ice core geodatabase for paleoclimatic and glaciological analyses. Geografia Fisica e Dinamica Quaternaria 39, 59-68. https://doi.org/10.4461/GFDQ.2016.39.6

Meiners, S., 2005. The glacial history of landscape in the Batura Muztagh, NW Karakoram. GeoJournal 63, 49-90. https://doi.org/10.1007/s10708-005-2396-9

Melis, M.T., Dessì, F., Locci, F., Bonasoni, P., Vuillermoz, E., 2013. Share Geonetwork: A web-service platform for environmental data sharing, in: Proceedings of SPIE - The International Society for Optical Engineering. https://doi.org/10.1117/12.2027602

Melis, M.T., Dessì, F., Loddo, P., La Mantia, C., Da Pelo, S., Deflorio, A.M., Ghiglieri, G., Hailu, B.T., Kalegele, K., Mwasi, B.N., 2017. FLOWERED-GEODBAPP: AN APPLICATION BASED ON CROWD-GENERATING DATA USING SENTINEL2 IMAGERY. ISPRS - International Archives of the Photogrammetry, Remote Sensing and Spatial Information Sciences XLII-4/W2, 121-127. https://doi.org/10.5194/isprsarchives-XLII-4-W2-121-2017

Melis, M.T., Locci, F., Dessì, F., Frigerio, I., Strigaro, D., M, D.A., Vuillermoz, E., 2014. NextData Project: development of a web system for climate and paleoclimate data sharing 31 , 2027602 .

Middleton, J., Lee, T., 2003. Guidelines for management planning of protected areas, Best Practice Protected Area Guidelines Series. Gland: IUCN, 2003.

Nawaz, M.A., Martin, J., Swenson, J.E., 2014. Identifying key habitats to conserve the threatened brown bear in the Himalaya. Biological Conservation 170, 198-206. https://doi.org/10.1016/j.biocon.2013.12.031

Nawaz, M.A., Swenson, J.E., Zakaria, V., 2008. Pragmatic management increases a flagship species, the Himalayan brown 
bears, in Pakistan's Deosai National Park. Biological Conservation 2230-2241. https://doi.org/10.1016/j.biocon.2008.06.012

Paul, F., Hendriks, J., 2009. Detection and visualization of glacier area changes, in: Remote Sensing of Glaciers. Taylor \& Francis, pp. 231-243. https://doi.org/10.1201/b10155-13

Yang, C., Everitt, J.H., Fletcher, R.S., Jensen, R.R., Mausel, P.W., 2009. Evaluating AISA + Hyperspectral Imagery for Mapping Black Mangrove along the South Texas Gulf Coast. Photogrammetric Engineering \& Remote Sensing 75, 425-435. https://doi.org/10.14358/PERS.75.4.425

Yoshikawa, K., Hinzman, L.D., 2003. Shrinking thermokarst ponds and groundwater dynamics in discontinuous permafrost near council, Alaska. Permafrost and Periglacial Processes 14, 151-160. https://doi.org/10.1002/ppp.451

Zhao, Y., Feng, D., Yu, L., See, L., Fritz, S., Perger, C., Gong, P., 2017. Assessing and Improving the Reliability of Volunteered Land Cover Reference Data. Remote Sensing 9. https://doi.org/10.3390/rs9101034 